\title{
Scale effect on overland flow connectivity at the plot scale
}

\author{
A. Peñuela ${ }^{1}$, M. Javaux ${ }^{1,2}$, and C. L. Bielders ${ }^{1}$ \\ ${ }^{1}$ Earth and Life Institute, Université catholique de Louvain, Croix du Sud 2, L7.05.02, 1348 Louvain-la-Neuve, Belgium \\ ${ }^{2}$ Agrosphere, IBG-3, Forschungszentrum Julich GmbH, 52425 Julich, Germany \\ Correspondence to: A. Peñuela (andres.penuela@uclouvain.be)
}

Received: 5 June 2012 - Published in Hydrol. Earth Syst. Sci. Discuss.: 25 June 2012

Revised: 30 November 2012 - Accepted: 7 December 2012 - Published: 14 January 2013

\begin{abstract}
A major challenge in present-day hydrological sciences is to enhance the performance of existing distributed hydrological models through a better description of subgrid processes, in particular the subgrid connectivity of flow paths. The Relative Surface Connection (RSC) function was proposed by Antoine et al. (2009) as a functional indicator of runoff flow connectivity. For a given area, it expresses the percentage of the surface connected to the outflow boundary $(C)$ as a function of the degree of filling of the depression storage. This function explicitly integrates the flow network at the soil surface and hence provides essential information regarding the flow paths' connectivity. It has been shown that this function could help improve the modeling of the hydrograph at the square meter scale, yet it is unknown how the scale affects the RSC function, and whether and how it can be extrapolated to other scales. The main objective of this research is to study the scale effect on overland flow connectivity (RSC function). For this purpose, digital elevation data of a real field $(9 \times 3 \mathrm{~m})$ and three synthetic fields $(6 \times 6 \mathrm{~m})$ with contrasting hydrological responses were used, and the RSC function was calculated at different scales by changing the length $(l)$ or width $(w)$ of the field. To different extents depending on the microtopography, border effects were observed for the smaller scales when decreasing $l$ or $w$, which resulted in a strong decrease or increase of the maximum depression storage, respectively. There was no scale effect on the RSC function when changing $w$, but a remarkable scale effect was observed in the RSC function when changing $l$. In general, for a given degree of filling of the depression storage, $C$ decreased as $l$ increased, the change in $C$ being inversely proportional to the change in $l$. However, this observation applied only up to approx. 50-70\% (depending on the hydrological response of the field) of filling of depression storage, after which no correlation was found between $C$ and
\end{abstract}

$l$. The results of this study help identify the minimal scale to study overland flow connectivity. At scales larger than the minimal scale, the RSC function showed a great potential to be extrapolated to other scales.

\section{Introduction}

The concept of connectivity, applied in many disciplines, aims at characterizing the behavior of heterogeneous systems according to the intrinsic organization of the heterogeneities. In the context of landscape connectivity, connectivity can be defined as the degree to which the landscape facilitates or impedes movement between resource patches (Taylor et al., 1993). In hydrology there is still no consensus about the definition of hydrological connectivity (Bracken and Croke, 2007; Ali and Roy, 2009). However, by analogy with the concept of landscape connectivity, overland flow connectivity can be defined as the degree to which the surface morphology facilitates or impedes overland flow. This definition, as well as the landscape connectivity concept, integrates two subconcepts: structural and functional connectivity (Tischendorf and Fahring, 2000). Structural connectivity describes the extent to which the surface morphology units, such as depressions, are linked to each other. It can be derived from topographical information. Functional connectivity describes the effect produced by the surface morphology on the process of overland flow. Functional connectivity must therefore be derived from a combination of topographical information and hydrological modeling.

Overland flow is a spatially distributed process affected by both the macro (meters) and micro (millimeters) scales. As the scale of study changes, different features of the surface become relevant and govern the hydrological response 
of the area of study. At the finest scale, soil roughness plays an important role through its effect on flow velocity. This extensively studied effect is incorporated in hydrological models as a friction factor. As the scale increases, the surface morphology increasingly influences overland flow (Darboux et al., 2002b). Indeed, the surface microtopography exerts a control over the infiltration process through its effects on the spatial heterogeneity of surface sealing (Langhans et al., 2011). Furthermore, the spatial configuration of the system, formed by water-contributing sources, water-accepting sinks (depressions) and connecting links (e.g., small rills between depressions), determines the hydrological response of the system. The study of the spatial configuration by geostatistics (e.g., the semivariogram) or landscape metrics allows comparison and classification of dominant processes and may partly explain the hydrological response. However, it is not adequate for predictive purposes in terms of hydrological response and connectivity (Van Nieuwenhuyse et al., 2011).

From the hillslope to the small watershed scale, distributed hydrological models frequently use "plot size" (1-1000 $\left.\mathrm{m}^{2}\right)$ grid cells allowing for an explicit analysis of overland flow connectivity. However, such hydrological models do not explicitly treat overland flow connectivity below the grid cell size. Overland flow processes in each grid cell are generally represented by two effective parameters, the maximum depression storage (i.e., maximum volume of water that the soil is able to store in surface depressions) and the friction factor (i.e., resistance to flow) (Singh and Frevert, 2002; Smith et al., 2007), which have been found neither to reflect overland flow processes realistically at the subgrid scale nor to allow for proper discrimination between different hydrological responses (Antoine et al., 2009).

Generally, hydrological models assume that the generation of overland flow only starts after the maximum depression storage is reached (Singh and Frevert, 2002). However, this assumption underestimates the surface connected to downstream areas and hence the volume of runoff generated before the complete filling of depressions (Antoine et al., 2011). In reality, depressions progressively overflow and water flows either to nearby depressions, or to the outflow boundary (Onstad, 1984; Darboux et al., 2002b). As depression storage increases, a larger area of the field becomes connected and contributes to the overland flow generation. This gradual process delays the initiation of the overland flow, and hence of the hydrograph. A better understanding of the connectivity dynamics, which drive the hydrological response of a system at different scales (Lexartza-Artza and Wainwright, 2009), should improve current hydrological modeling and runoff prediction (Western et al., 2001; Mueller et al., 2007).

In order to fully take into account overland flow connectivity at the hillslope and small watershed scale, it would be necessary to provide hydrological models with subgrid microtopographical information. The use of a high resolution DEM (cm-mm resolution) in hydrological models would strongly increase the input data and the computation time requirements. Yet even more problematic would be the acquisition of such data over large areas. Hence, subgrid connectivity functions, able to differentiate between different surface morphologies having different hydrological responses, must be developed in order to improve the prediction of flows at the hillslope and small watershed-scale scale without critically increasing computation time and data requirements of distributed hydrological models.

As subgrid connectivity is expected to be scale-dependent, extra attention must be paid in order to select an appropriate size of the grid cell. Some studies have reported the existence of a representative elementary area (Wood et al., 1988) or length scale (Julien and Moglen, 1990) that could serve to determine the grid cell scale in hydrological models. Firstly, the grid cell must be sufficiently large to be representative of the process of overland flow connectivity at the plot scale, i.e., all the components and the relationships between them must be represented (Ali and Roy, 2009). Secondly, it must minimize border effects so as to neither miss nor modify some of these components. In addition, slope length has been observed to influence the response of the overland flow, showing a lower runoff coefficient with increasing length (Van de Giessen et al., 2000; Cerdan et al., 2004). It has generally been assumed that this results from the spatial variability of rainfall and infiltration capacity (Yair and Lavee, 1985). Yet this effect has also been observed on homogenous hillslopes, in which case it was attributed to a change in residence time (Stomph et al., 2002). According to the definition of overland flow connectivity mentioned above, connectivity is expected to decrease with increasing slope lengths, since the probability for the water flow to encounter depressions is higher. However, the effect of slope length on overland flow connectivity and the runoff coefficient is still unclear.

In order to analyze and quantify the effect of scale on overland flow connectivity, a functional connectivity indicator was selected, the so-called Relative Surface Connection (RSC) function (Antoine et al., 2009). It expresses the percentage of the surface connected to the outflow boundary of a grid element as a function of the degree of filling of the depression storage. This function explicitly integrates the flow network at the soil surface and hence provides essential information regarding the flow paths' connectivity. It can be calculated much faster than the full resolution of the St. Venant equations and it has shown good results in capturing runoff-relevant connectivity properties compared to other connectivity indicators (Antoine et al., 2009). By adding surface detention dynamics to the RSC function (Antoine et al., 2011), this connectivity function also allowed to simulate in a simple way experimental hydrographs. Moreover, it could potentially be integrated in hydrological models in a manner similar to the Probability Density Model (PDM) (Moore, 2007), which implements the subgrid variability of the "soil absorption capacity" as a probability density curve.

The RSC function showed very promising results at the square meter scale but, as a functional connectivity indicator, 
it may be scale-dependent and affected by border effects. However, it is unknown how changes in scale affect the RSC function and whether and how the RSC function can be extrapolated to other scales.

The objective of this study is therefore twofold. The first objective is to study the effect of changing scale on the RSC function for scales ranging from $0.18 \mathrm{~m}^{2}$ to $36 \mathrm{~m}^{2}$. The second objective is to investigate the potential of the RSC function to be extrapolated to larger scales. For these purposes, the RSC function will be calculated and compared at different scales and for different microtopography types. The present study focuses on the hydrological connectivity at the plot scale, considering no interferences from infiltration, i.e., the infiltration capacity of the soil is assumed to be spatially homogeneous, constant over time and lower than the rainfall intensity. These assumptions, which do not take into account the effect of the spatial heterogeneity of the soil hydraulic conductivity on surface runoff (Langhans et al., 2011), nevertheless facilitate the study of the effects of the surface morphology and scale on overland flow.

\section{Materials and method}

\subsection{Characteristics of the microtopographies}

Two types of DEMs were used, real and synthetic. First, we used the DEM from a field located near Fort Collins, Colorado (USA), obtained by laser scanning (courtesy of the USDA-ARS Agricultural Systems Research Unit in Fort Collins). The field had been under grassland but the grass had been killed chemically and left to decay before scanning. The total size of the DEM is $9.5 \mathrm{~m} \times 4.8 \mathrm{~m}$, the spatial $x-y$ resolution is $1.5 \mathrm{~mm}$ and the vertical resolution is $0.5 \mathrm{~mm}$. The natural slope of the field is $6.6 \%$. In order to avoid border effects that may have been generated during the process of obtaining the DEM, this study focuses on the central area, with a size of $9 \mathrm{~m} \times 3 \mathrm{~m}$. This was also guided by the need to have three square replicate areas of the largest possible size (in this case, $3 \mathrm{~m} \times 3 \mathrm{~m}$ ). For computational reasons, the spatial $x-y$ resolution of the DEM was reduced to $3 \mathrm{~mm}$. The semi-variograms of the three replicates had a range of approximately $600 \mathrm{~mm}$ and a sill of $80-110 \mathrm{~mm}^{2}$ (Table 1).

Secondly, in order to evaluate the scale effect in scenarios with different hydrological characteristics and connectivity patterns, synthetic fields with contrasting microtopographies were generated using a method developed by Zinn and Harvey (2003) and adapted by Antoine et al. (2009). The synthetic fields present identical statistics in terms of mean elevation, standard deviation and semivariogram. However, they have different connectivity patterns. This method also allowed us to study the scale effect at larger scales compared to the real field case, yet the size of the fields was nevertheless limited for computational reasons. Three different types of microtopographies were generated using
Table 1. Main characteristics of the microtopographies.

\begin{tabular}{lllll}
\hline & & \multicolumn{3}{c}{ Synthetic Fields } \\
\cline { 3 - 5 } & Real field & River & Random & Crater \\
\hline Size $[\mathrm{m} \times \mathrm{m}]$ & $3 \times 3$ & $6 \times 6$ & $6 \times 6$ & $6 \times 6$ \\
Spatial resolution $\left[\mathrm{mm} \mathrm{pixel}^{-1}\right]$ & 3 & 10 & 10 & 10 \\
Slope [\%] & 6.6 & 6.6 & 6.6 & 6.6 \\
Standard deviation of elevation $[\mathrm{mm}]$ & 1.8 & 1.3 & 1.3 & 1.3 \\
Semivariogram - sill $\left[\mathrm{mm}^{2}\right]$ & $80-110$ & 100 & 100 & 100 \\
Semivariogram - range $[\mathrm{mm}]_{\text {Depression storage [mm] }}$ & 600 & 100 & 100 & 100 \\
Percolation threshold & 0.53 & 0.5 & 1.275 & 2.55 \\
[relative depression storage] & 0.66 & 0.77 & 0.75 & 0.73 \\
\hline
\end{tabular}

this method: (a) "river", (b) "crater" and (c) "random" type (Fig. 1; Antoine et al., 2009). The "river" type microtopography presents high areas connected by a system of rills. On the other hand, the "crater" type, which is the reverse of the river type, presents a system of crests that isolate the depressions from each other. The "random" type microtopography is an intermediate scenario represented by a standard multi-Gaussian synthetic field. The three synthetic fields are characterized by values of sill $\left(100 \mathrm{~mm}^{2}\right)$ and range $(100 \mathrm{~mm})$ of the semivariogram also observed in real fields (Vidal Vazquez et al., 2005) and experimental plots (Darboux et al., 2002b). A slope equal to the natural slope $(6.6 \%)$ of the real field was also added.

\subsection{Filling algorithm and Relative Surface Connection (RSC) function}

A filling algorithm (Antoine et al., 2009) was used to evaluate the overland flow connectivity. This method calculates a simplified hydrograph in which the velocity of the water is infinite and infiltration is not considered. A uniform rainfall is applied over the digital elevation model (DEM) of the study area. At every time step, a certain volume of water is applied in every pixel of the DEM. These volumes of water "walk" over the DEM to the lowest pixel selected by an 8-neighbor scheme until they reach a depression or the outflow boundary. In a depression, this volume of water is stored as depression storage. Once the depression overflows, any excess of water flows to the next depression or to the outflow boundary. Since the water velocity is infinite, surface detention, i.e. water that is not trapped in depressions, is removed at every time step (Antoine et al., 2012). When a drop reaches the outflow boundary it is added to the hydrograph. Since both the infiltration and the transfer time are nil, the ratio of instantaneous outflow to the instantaneous inflow corresponds to the percentage of the total area connected to the outflow boundary $(C)$. Thus, this ratio will be equal to 1 when $100 \%$ of the surface of the study area is connected to the outflow boundary. At that point, depression storage reaches its maximum value, i.e., the dead storage zone is completely filled.

The relative area connected to the outflow boundary can be represented in a simplified hydrograph as a function of 

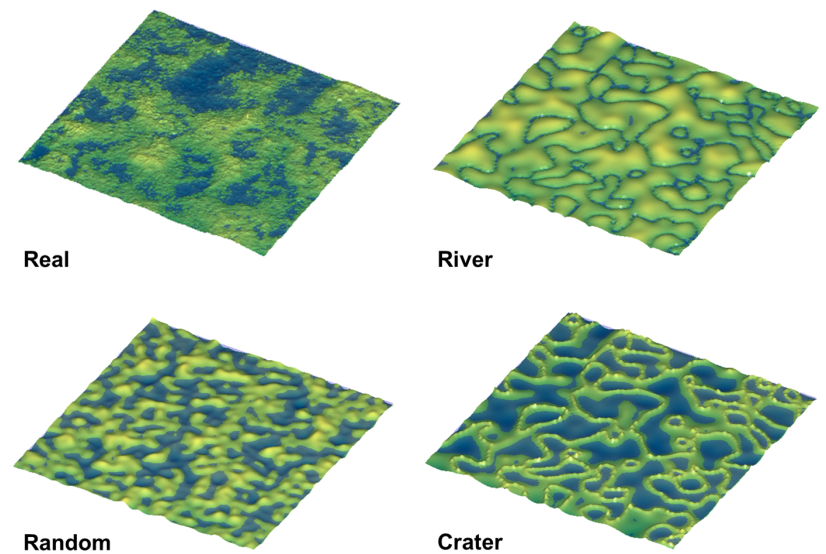

River

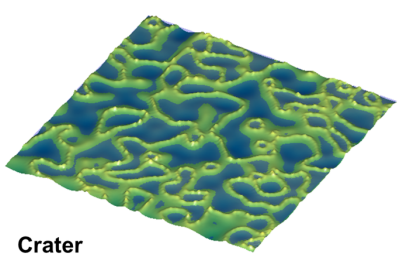

Fig. 1. Detail of the four microtopography types $(2 \mathrm{~m} \times 2 \mathrm{~m})$ with depressions partially filled with water (in blue) in order to highlight the contrasting connectivities.

the cumulative input of water. In this case, the area under the simplified hydrograph is equal to the cumulative volume of outflow $\left[\mathrm{m}^{3}\right]$ and the area between $C=1$ and the simplified hydrograph corresponds to the MDS (maximum depression storage). Based on this, we can represent $C$ as a function of the depression storage (Fig. 2). This is known as the Relative Surface Connection (RSC) function, which is a functional connectivity indicator that is able to discriminate well among surfaces with differing levels of connectivity and that can potentially be implemented in hydrological models (Antoine et al., 2009).

\subsection{Process of plot fragmentation and calculation of the RSC function}

Two different scale effects were considered, i.e., changing the width of the plot area and changing the length of the plot area. Therefore, the area was first divided into narrower areas (from $1 / 2$ up to $1 / 32$ of the initial width) keeping the initial length constant, and secondly the area was divided into shorter areas (from 1/2 up to 1/32 of the initial length) keeping the initial width constant (Fig. 3). The process of fragmentation of the plots and the calculation of the RSC function was exactly the same for all the fields. After the plot areas were divided, the filling algorithm was run in each of these sub-areas in order to obtain their RSC function. Finally, for a given scale, the RSC functions obtained in each subarea were averaged in order to compare overland flow connectivity at different scales.

\subsection{Representative width and length}

In order to identify the minimal scale at which overland flow connectivity can be studied, a representative width and length were defined. Since border effects are expected to mainly cause variations in the MDS of the field, the representative

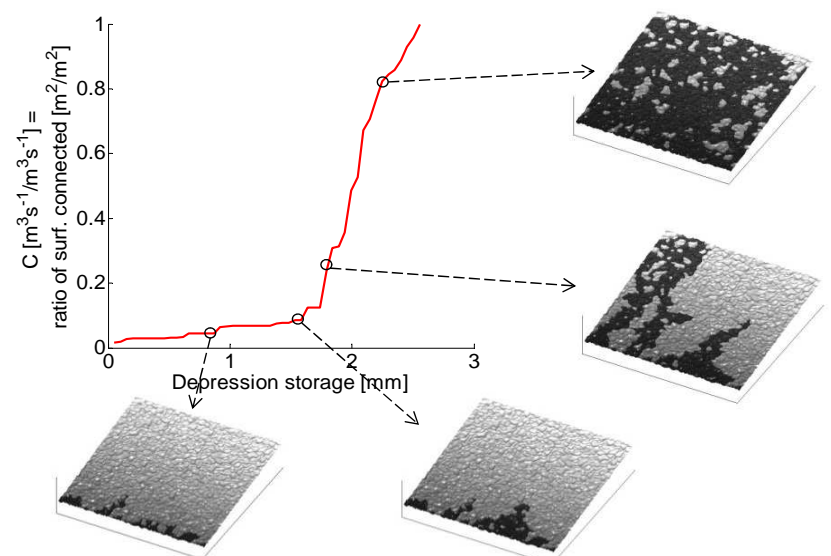

Fig. 2. Example of Relative Surface Connection (RSC) function and connectivity evolution (areas connected to the bottom boundary are shown in black).

width and length will be defined in function of the observed change in the MDS. Although the full width and legth of the plot are needed to estimate the MDS with the highest accuracy, in practice, a small error on the estimation of the MDS may be acceptable. This acceptable error was arbitrarily set at $10 \%$ of the MDS when $w \rightarrow \infty$ or $l \rightarrow \infty$ in the present study. The value of the corresponding width and length will be referred to as the "representative width" (Table 2) and "representative length" (Table 3), and will be used to quantify and compare the scale effects between the four microtopography types.

\section{Results}

\subsection{Real field}

\subsubsection{Scale effect produced by changing only the width}

When representing the average RSC function for each width in the same graph (Fig. 4a), a gradual shift of the RSC function to the left is observed, indicating a gradual decrease of the MDS with increasing width. This decrease in MDS is inversely proportional to the width, tending asymptotically to a constant value (Fig. 4b). This can be represented adequately by the following expression (Eq. 1):

$\operatorname{MDS}(w)=\frac{k}{w}+v$

where MDS is the maximum depression storage [mm] for a given width $w[\mathrm{~mm}]$ of the plot, $k$ [mm] is a constant (Table 2) whose value reflects the magnitude of the asymptotic decrease of the MDS when increasing the width of the plot, and $v$ represents the MDS when $w$ tends to infinity $\left(\operatorname{MDS}_{w \rightarrow \infty}\right)$. 

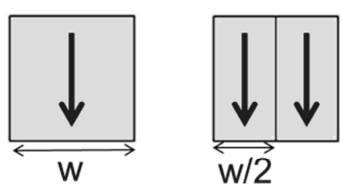

(a)
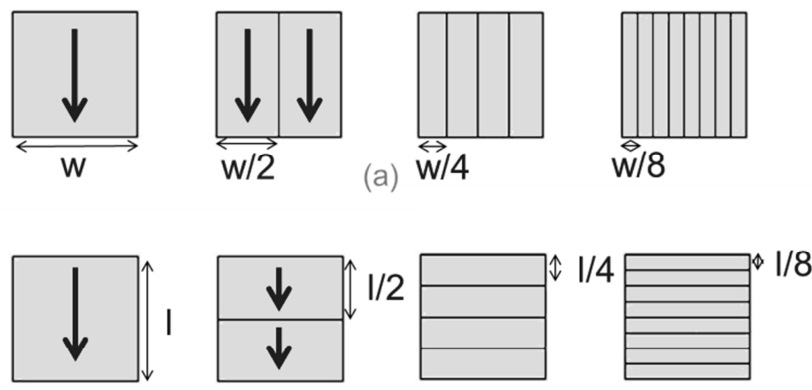

(b)

Fig. 3. Division pattern when changing (a) width and (b) length of the plots.

Table 2. Parameters of Eq. (1) when changing width $(w)$, goodness of fit expressed as the sum of squares (SS) and the pseudo $R$-squared, and representative width for the four microtopography types.

\begin{tabular}{lrrrrrr}
\hline & $\begin{array}{r}\text { MDS } \\
{[\mathrm{mm}]}\end{array}$ & $\begin{array}{r}k \\
{[\mathrm{~mm}]}\end{array}$ & $\begin{array}{r}v \\
{[\mathrm{~mm}]}\end{array}$ & $\begin{array}{r}\text { Sum of } \\
\text { squares } \\
{\left[\mathrm{mm}^{2}\right]}\end{array}$ & $\begin{array}{r}\text { Pseudo } \\
R \text {-squared }\end{array}$ & $\begin{array}{r}\text { Representative } \\
\text { width } \\
{[\mathrm{mm}]}\end{array}$ \\
\hline Real & 0.53 & 60 & 0.51 & 0.00036 & 0.99860 & 1200 \\
River & 0.5 & 145 & 0.47 & 0.00451 & 0.96952 & 2500 \\
Random & 1.275 & 129 & 1.26 & 0.00102 & 0.99131 & 1100 \\
Crater & 2.55 & 222 & 2.52 & 0.00145 & 0.97064 & 900 \\
\hline
\end{tabular}

A "representative width" can be defined based on an acceptable error of $10 \%$ on $\operatorname{MDS}_{w \rightarrow \infty}$ (Table 3). This acceptable error is represented in Fig. $4 \mathrm{~b}$ as dashed lines.

In order to compare the shape of the different RSC functions, the depression storage was normalized by the value of the maximum depression storage for each scale (Fig. 5). This way of representing the RSC function shows that the shape is little affected by width except for the two smallest scales (width $=0.188 \mathrm{~m}$ and $0.09 \mathrm{~m}$ ), which present a strong deviation in the last third of the function (relative depression storage approximately $>2 / 3$ ). These two curves show a displacement to the right, i.e., for the same value of relative depression storage the connectivity is lower for the two smallest scales as compared to the larger scales.

\subsubsection{Scale effect produced by changing only the length}

When changing the length for a constant width of $3 \mathrm{~m}$, the average RSC functions show the opposite trend than was observed when changing the width. The RSC function shows a gradual shift to the right as the plot length increases (Fig. 6a), i.e., a gradual increase of the MDS with increasing length. This increase in MDS with plot length can also be fitted adequately by Eq. (1), after replacing $w$ by $l$ and with $k<0$ (Fig. 6b). The corresponding parameters are provided in Table 3. In this case, $v$ represents the MDS when $l$ tends to infinity $\left(\operatorname{MDS}_{l \rightarrow \infty}\right)$.
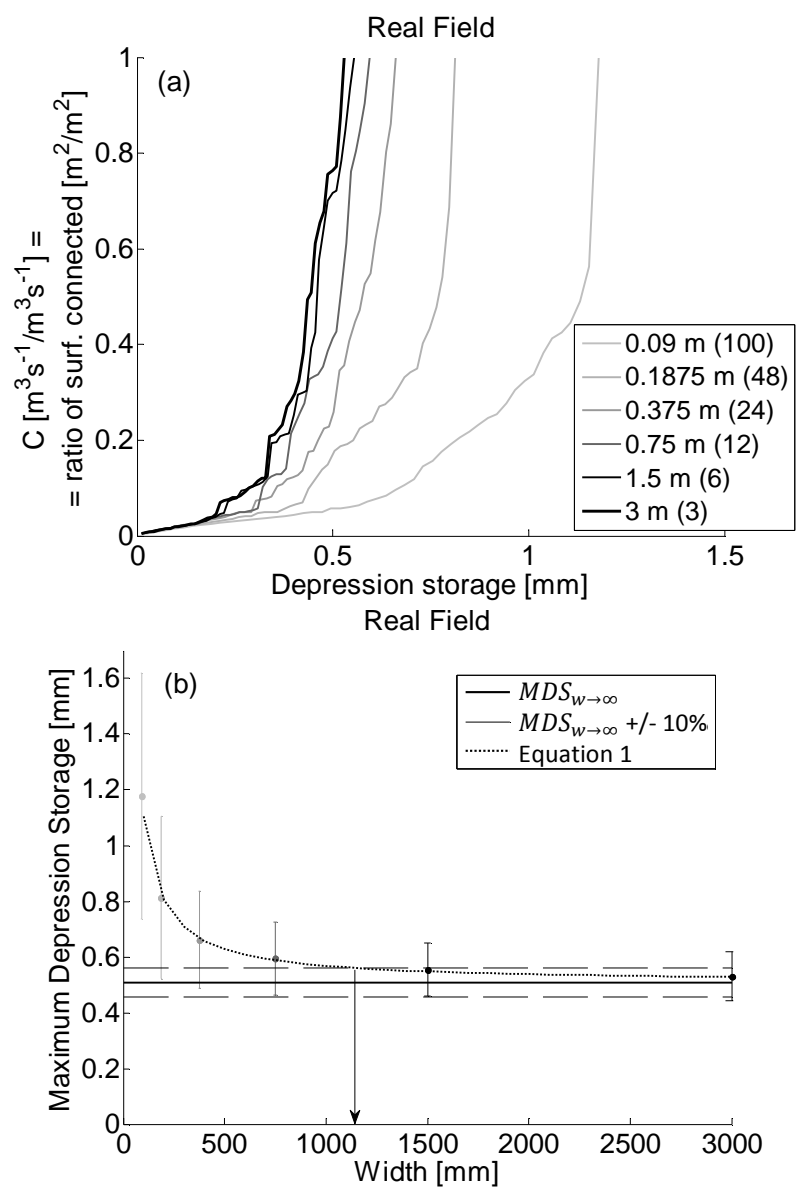

Fig. 4. Real field - effect of plot width on the average RSC function (a) and on the maximum depression storage (MDS) (b). The numbers in parentheses indicate the number of connectivity curves used for calculating the average RSC functions. Vertical bars = standard deviations. The arrow indicates the representative width. All the plots are $3 \mathrm{~m}$ long.

As was done for width, a "representative length" can be defined based on an acceptable error of $10 \%$ on $\operatorname{MDS}_{l \rightarrow \infty}$ (Table 3). This acceptable error is represented in Fig. $6 \mathrm{~b}$ as dashed lines.

Unlike what was observed when changing width, changing length not only changes the MDS but also the shape of the RSC function (Fig. 7). The shorter the slope length, the higher the connectivity is for the same value of relative depression storage. The RSC function tends from a concave shape for the largest plot lengths to a straighter or even convex shape, especially for the smallest scales (length $=0.1875 \mathrm{~m}$ and $0.09 \mathrm{~m}$ ). 
Table 3. Parameters of Eq. (1) when changing length $(l)$, goodness of fit expressed as the sum of squares (SS) and the pseudo $R$-squared, and representative length for the four microtopography types.

\begin{tabular}{lrrrrrr}
\hline & $\begin{array}{r}\text { MDS } \\
{[\mathrm{mm}]}\end{array}$ & $\begin{array}{r}k \\
{[\mathrm{~mm}]}\end{array}$ & $\begin{array}{r}v \\
{[\mathrm{~mm}]}\end{array}$ & $\begin{array}{r}\text { Sum of } \\
\text { squares } \\
{\left[\mathrm{mm}^{2}\right]}\end{array}$ & $\begin{array}{r}\text { Pseudo } \\
R \text {-squared }\end{array}$ & $\begin{array}{r}\text { Representative } \\
\text { length } \\
{[\mathrm{mm}]}\end{array}$ \\
\hline Real & 0.53 & -23 & 0.55 & 0.00059 & 0.93334 & 400 \\
River & 0.5 & -16 & 0.50 & 0.00009 & 0.95344 & 300 \\
Random & 1.275 & -71 & 1.29 & 0.00026 & 0.98167 & 600 \\
Crater & 2.55 & -237 & 2.57 & 0.00385 & 0.99702 & 950 \\
\hline
\end{tabular}

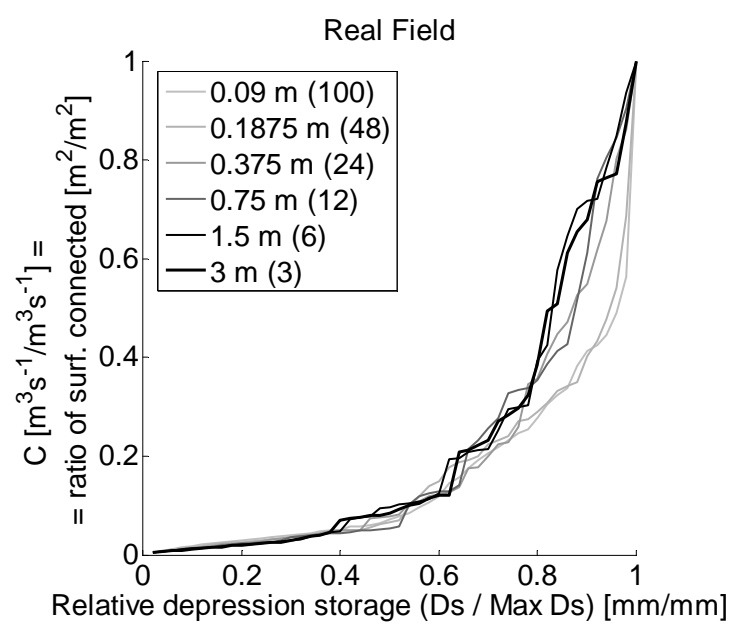

Fig. 5. Real field - effect of plot width on the normalized RSC function. Depression storage (x-axis) was scaled by the maximum depression storage. The numbers in parentheses indicate the number of connectivity curves used for calculating the average normalized RSC functions. All the plots are $3 \mathrm{~m}$ long.

\subsection{Synthetic Fields}

\subsubsection{Scale effect produced by changing only the width}

As for the real field, when increasing the plot width, a gradual shift of the RSC function to the left is observed (Fig. 8), reflecting a gradual decrease of the MDS. MDS decreases asymptotically towards a constant value as the width is increased (Fig. 9), which can be represented adequately by Eq. (1). The corresponding parameters are provided in Table $2 . \mathrm{MDS}_{w \rightarrow \infty}$ increases gradually from the river to the crater topography. As indicated by the k-values, the asymptotic decrease of MDS with increasing widths is most pronounced for the crater microtopography. However, as the representative width is determined based on an acceptable relative error of $10 \%$ on the estimation of $\mathrm{MDS}_{w \rightarrow \infty}$, the river microtopography is characterized by a higher representative width $(2500 \mathrm{~mm})$ as compared to the random and crater microtopographies that show smaller yet similar representative widths $(1100 \mathrm{~mm}$ and $900 \mathrm{~mm}$ respectively).
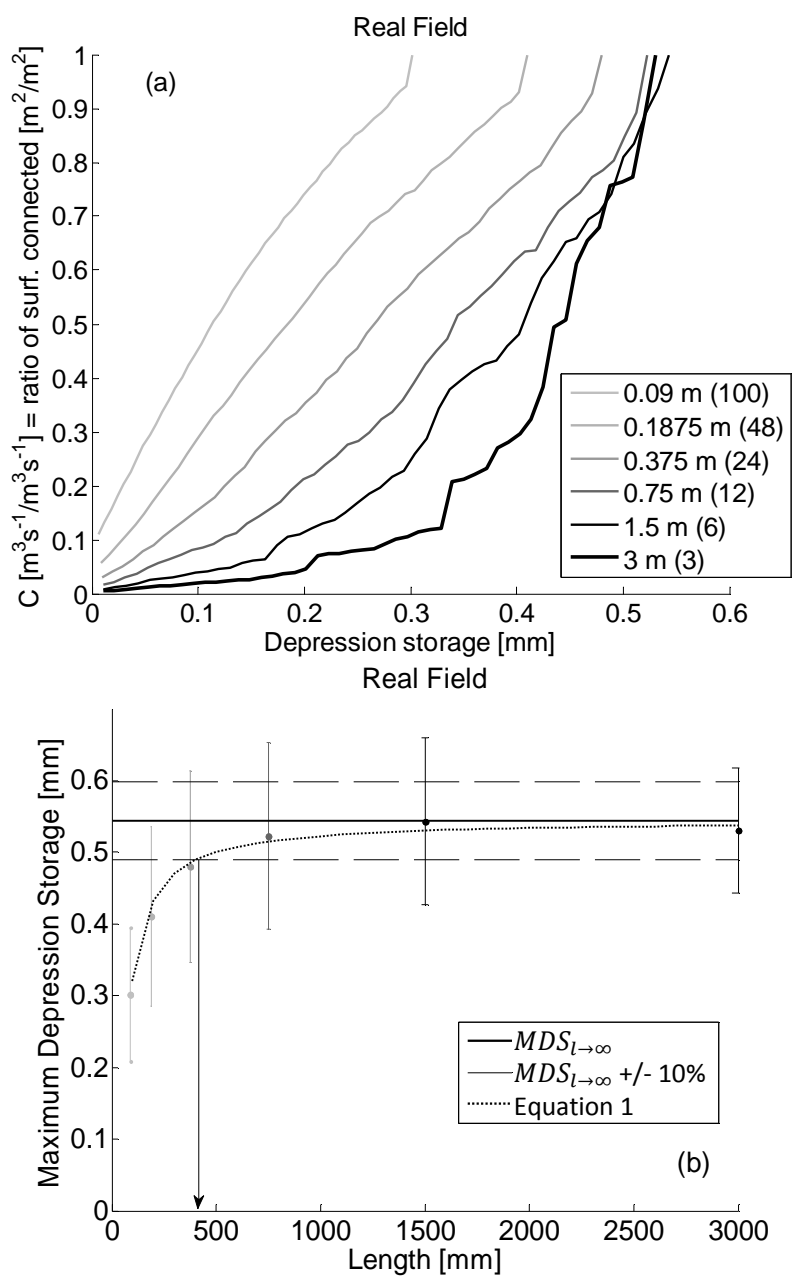

Fig. 6. Real field - effect of plot length on the average RSC function (a) and on the maximum depression storage (MDS) (b). The numbers in parentheses indicate the number of connectivity curves used for calculating the average RSC functions. Vertical bars $=$ standard deviations. The arrow indicates the representative length. All the plots are $3 \mathrm{~m}$ wide.

The shape of the RSC function, as for the real field, is little affected by a change in width, except for the smallest values of width (Fig. 10). For the random and river types, this deviation is only observable at the two smallest scales (width $=0.375 \mathrm{~m}$ and $0.188 \mathrm{~m}$ ) in the last third of the RSC function. For the crater type, a deviation is also noticeable in the last third of the RSC function for the intermediate widths (width $=0.75 \mathrm{~m}$ and $1.5 \mathrm{~m}$ ).

\subsubsection{Scale effect produced by changing only the length}

When reducing the length and keeping the initial width $(6 \mathrm{~m})$, the average RSC functions show the opposite effect compared to when changing the width, just like the real field. Again, there is a gradual shift of the RSC to the right with increasing length (Fig. 11). The MDS increases asymptotically 


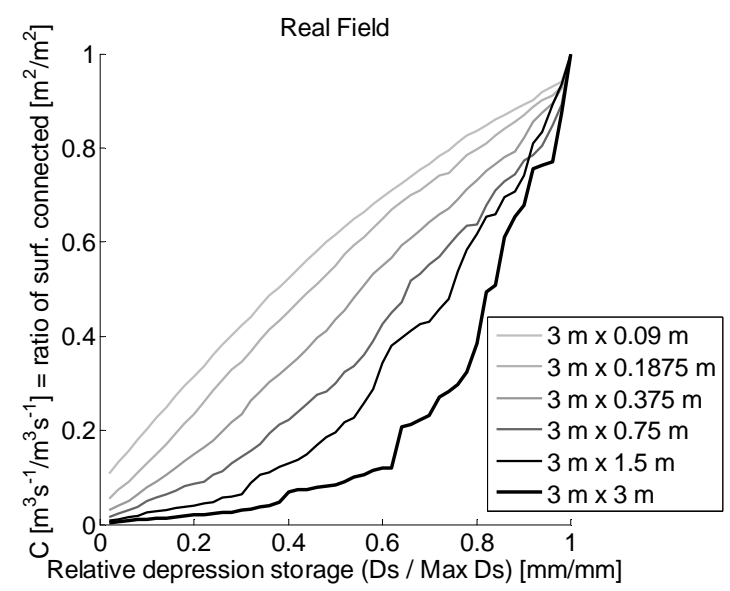

Fig. 7. Real field - effect of plot length on the normalized RSC function. Depression storage (x-axis) was scaled by the maximum depression storage. The numbers in parentheses indicate the number of connectivity curves used for calculating the average normalized RSC functions. All the plots are $3 \mathrm{~m}$ wide.

towards a constant value as the length increases (Fig. 12), which can be fitted by Eq. (1) after replacing $w$ by $l$. The corresponding values of $k(k<0)$ and $v$ are given in Table 3. As indicated by the $\mathrm{k}$-values, the river microtopography tends more rapidly to its asymptotic value than the random or crater microtopographies. The representative length increases from the river $(300 \mathrm{~mm})$ to the crater type $(950 \mathrm{~mm})$.

As for the real field, a reduction in length not only causes a decrease in MDS but also a change in the shape of the RSC functions. For a given value of the relative depression storage, a decrease in connectivity is observed as the length increases (Fig. 13). The RSC function tends from a concave shape for the largest plot lengths to a straighter or even convex shape, especially for the smallest scales (length $=0.375 \mathrm{~m}$ and $0.188 \mathrm{~m}$ ). The change in the shape of the RSC function is least pronounced for the river type and most pronounced for the crater type.

\section{Discussion}

\subsection{Scale effect on the MDS}

For all the cases studied, a gradual increase or decrease of the MDS has been observed when decreasing the width or the length, respectively. This can be explained by the increasing influence of the lateral and bottom boundaries when reducing the scale, i.e., by two border effects. On the one hand, the reduction of the width causes the interruption of the connecting paths between depressions (Figs. $4 \mathrm{~b}$ and 9). Below a certain scale, the deviation of the MDS from the $\operatorname{MDS}_{w \rightarrow \infty}$ starts to be considerable. Below this scale, the area between the virtual lateral plot boundaries is not able to represent adequately all the components involved in the functional
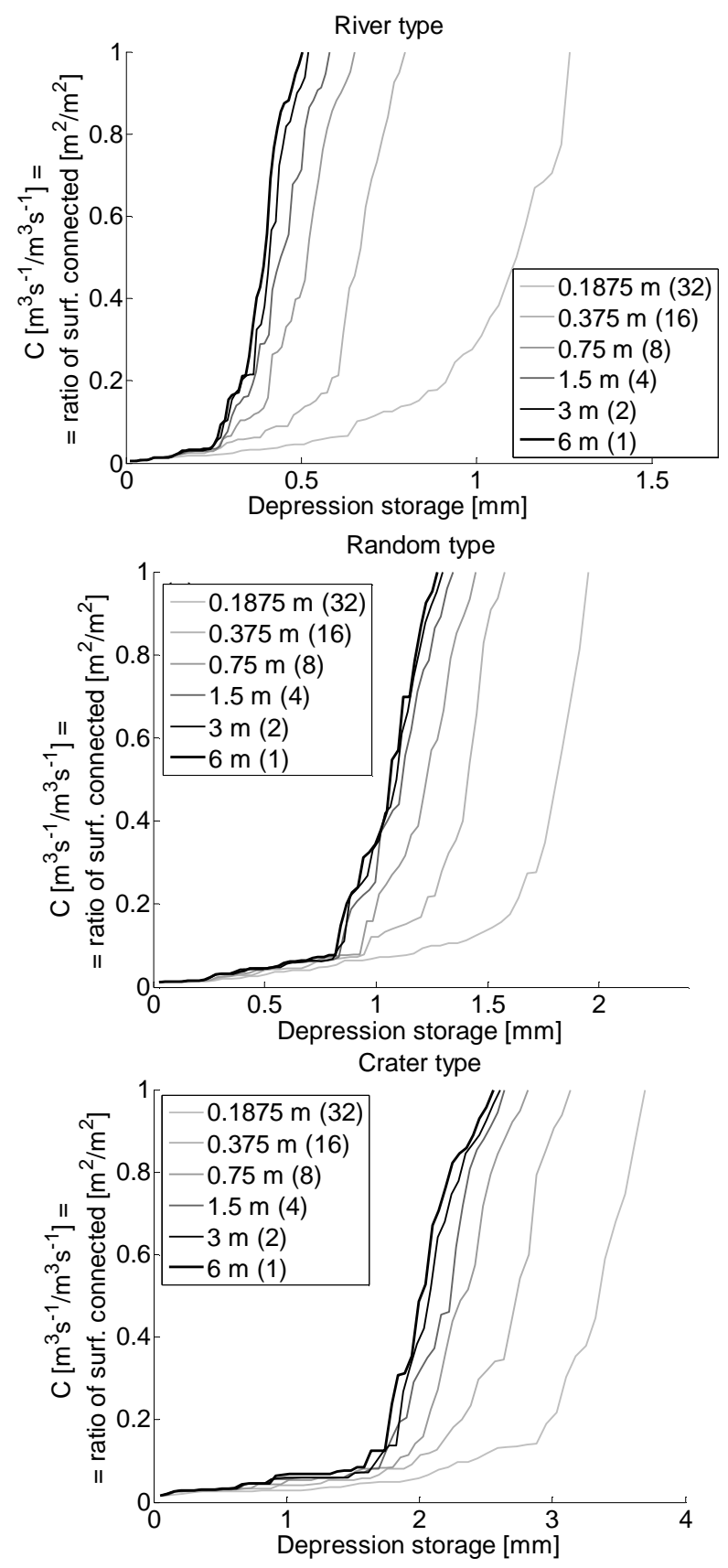

Fig. 8. Synthetic fields - effect of plot width on the averaged RSC function for the river, random and crater type microtopographies. The numbers in parentheses indicate the number of connectivity curves used for calculating the average RSC functions. All plots are $6 \mathrm{~m}$ long.

connectivity process. The connections between depressions are not completely included in this area and consequently water has to find new paths to reach the outflow boundary. These new paths require higher levels of stored water, i.e., the depth of water needed to overflow the depressions gets higher, and consequently the value of MDS increases. On 


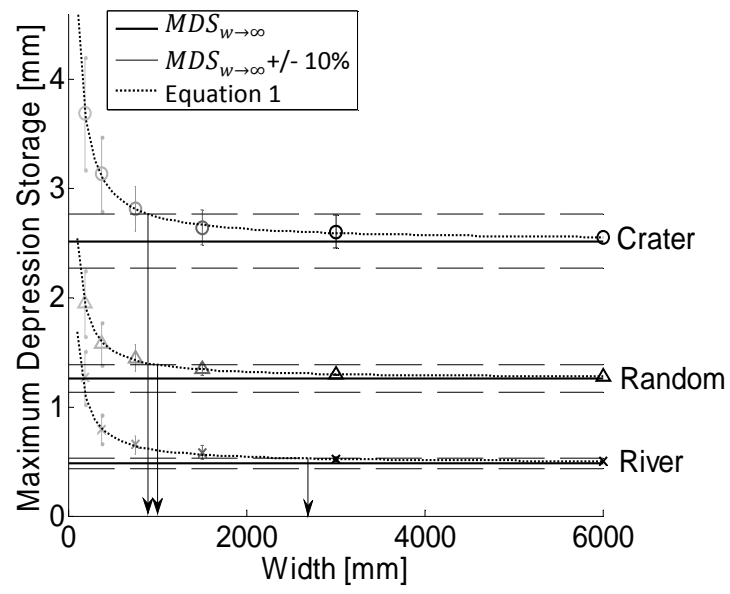

Fig. 9. Synthetic fields - effect of plot width on the maximum depression storage for the river, random and crater type microtopographies. Vertical bars $=$ standard deviations. The arrows indicate the representative width. All the plots are $6 \mathrm{~m}$ long.

the other hand, when the plot length is reduced below a certain scale (Figs. 6b and 12), the resulting area becomes less and less representative of all the components that cause the accumulation of water in the depressions (i.e., barriers in the direction of flow). In other words, as the length decreases, a larger proportion of depressions gets crossed by the virtual downstream outflow boundary, and hence they get more easily connected to it.

These two border effects affect all the microtopography types similarly in a qualitative way but differently in a quantitative way. In order to quantify and compare these effects between the different microtopography types, a representative scale was defined based on an acceptable deviation of the MDS by $10 \%$ from its asymptotic value (Figs. $4 \mathrm{~b}, 6 \mathrm{~b}$, 9, and 12). This representative scale represents the width or length below which the border effects start to be considerable, i.e., the plot is neither long enough nor wide enough to be representative of the process of overland flow connectivity occurring at larger scales. A $10 \%$ deviation from $\operatorname{MDS}_{w \rightarrow \infty}$ or $\mathrm{MDS}_{l \rightarrow \infty}$ was selected since smaller deviations of the MDS would barely affect results in hydrological modeling. Indeed, in our study, $\mathrm{MDS}_{w \rightarrow \infty}$ or $\mathrm{MDS}_{l \rightarrow \infty}$ values ranged from $0.5 \mathrm{~mm}$ to $2.5 \mathrm{~mm}$, such that a $10 \%$ relative error would lead to an absolute error comprised between $0.05 \mathrm{~mm}$ and $0.25 \mathrm{~mm}$. We believe that having a greater accuracy on the MDS would not be relevant for most practical applications, whereas accepting a higher relative error, especially in fields with high values of MDS, might lead to a substantial bias in hydrograph estimation.

The proposed representative scale provides a measure of the sensitivity of the different microtopographies to these two border effects. It is calculated using Eq. (1) (Tables 2 and 3). When plotted as a function of $\operatorname{MDS}_{w \rightarrow \infty}$ or $\operatorname{MDS}_{l \rightarrow \infty}$
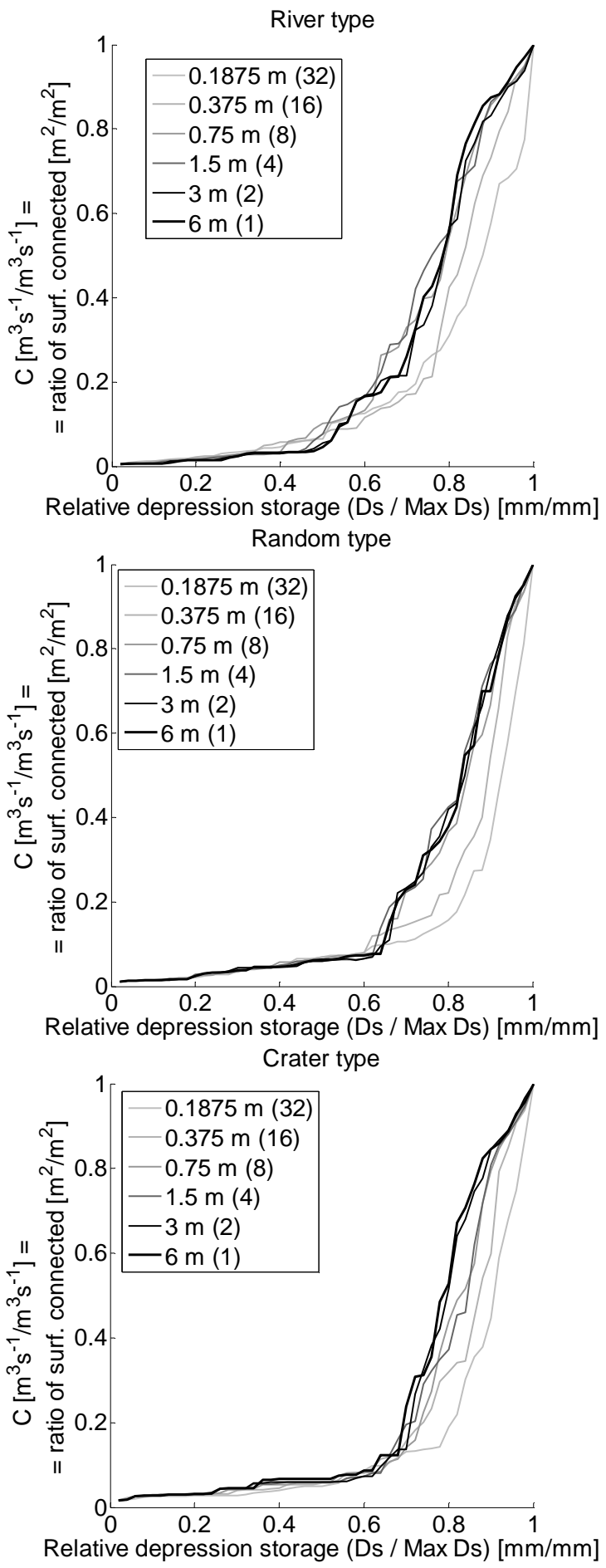

Fig. 10. Synthetic fields - effect of plot width on the average normalized RSC function for the river, random and crater type microtopographies. Depression storage (x-axis) was scaled by the maximum depression storage. The numbers in parentheses indicate the number of connectivity curves used for calculating the average normalized RSC functions. All plots are $6 \mathrm{~m}$ long. 

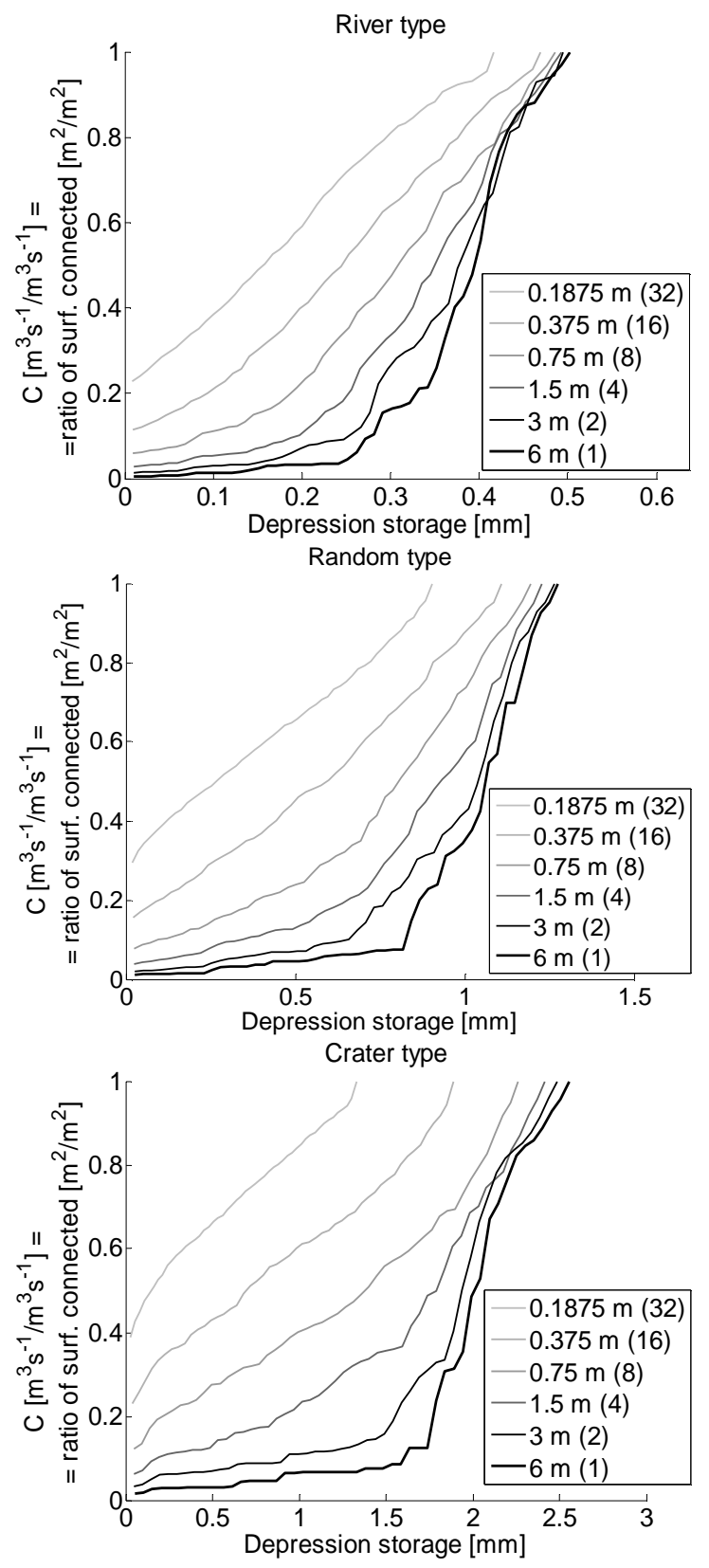

Fig. 11. Synthetic fields - effect of plot length on the averaged RSC function for the river, random and crater type microtopographies. The numbers in parentheses indicate the number of connectivity curves used for calculating the average RSC functions. All plots are $6 \mathrm{~m}$ wide.

(Fig. 14a and b), the sensitivity of the four microtopography types to scaling can be compared.

On the one hand, Fig. 14a shows a decrease of the representative width as the $\operatorname{MDS}_{w \rightarrow \infty}$ increases. This decrease seems to follow a linear trend except for the river microtopography whose representative width is approximately double of the real microtopography, even though they both have approximately the same value of $\operatorname{MDS}_{w \rightarrow \infty}$. This shows a

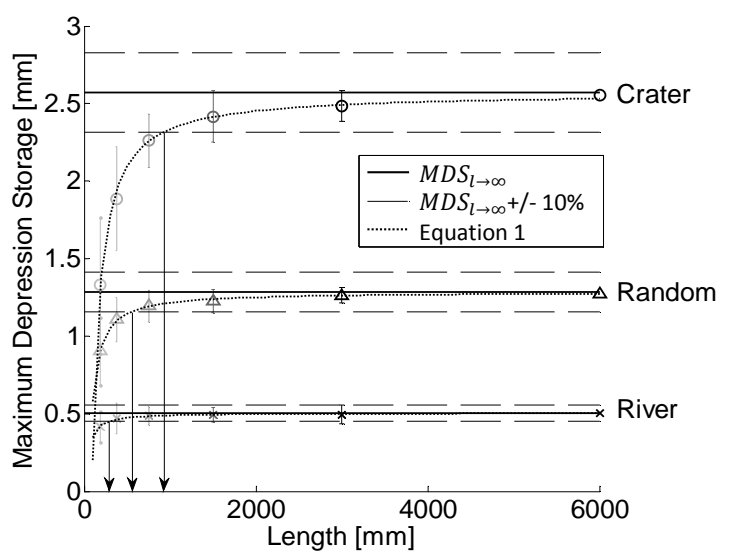

Fig. 12. Synthetic fields - effect of plot length on the maximum depression storage for the river, random and crater type microtopographies. Vertical bars = standard deviations. The arrows indicate the representative length. All the plots are $6 \mathrm{~m}$ wide.

higher sensitivity of the MDS to changes in width for the river microtopography compared to the other microtopographies. On the other hand, Fig. 14b shows an increase of the representative length as the $\mathrm{MDS}_{l \rightarrow \infty}$, increases. This increase seems to be approximately linear and, as opposed to the width border effect, the length border effect shows the highest sensitivity to changes in length for the crater microtopography and a lowest sensitivity for the river one.

These differences between the width and the length border effect and between different microtopographies can be explained by the preferential directions of flow and the different mechanisms of overland flow connectivity. Since a constant slope of $6.6 \%$ was applied to all the microtopographies, the preferential direction of flow is expected to follow the maximum slope direction, parallel to the lateral boundaries, until the bottom boundary. However, flow paths in the direction perpendicular to the lateral boundaries may also be important for the overland flow connectivity. This is the case of the river microtopography, which is the most sensitive to the width border effect. The mechanism of overland flow connectivity in this microtopography type is based on connections by a system of narrow rills which do not follow a preferential direction. When these rills are blocked by the virtual lateral boundaries, water must overflow higher areas of the plot to flow either to other rills or down to the bottom boundary. As a consequence, the overland flow process changes from a connectivity-driven process to an overflow-driven process as width decreases, causing a higher storage of water inside the disconnected areas, i.e., an increase of the MDS. On the contrary, connectivity in the crater microtopography, which is the least sensitive to the width border effect, is already driven by an overflow mechanism, meaning that water stored in depressions must overflow the system of crests to flow either to other depressions or down to the outflow boundary. In this case, water overflows the crests located at the lower part of the depressions, thus overland flow tends to follow 

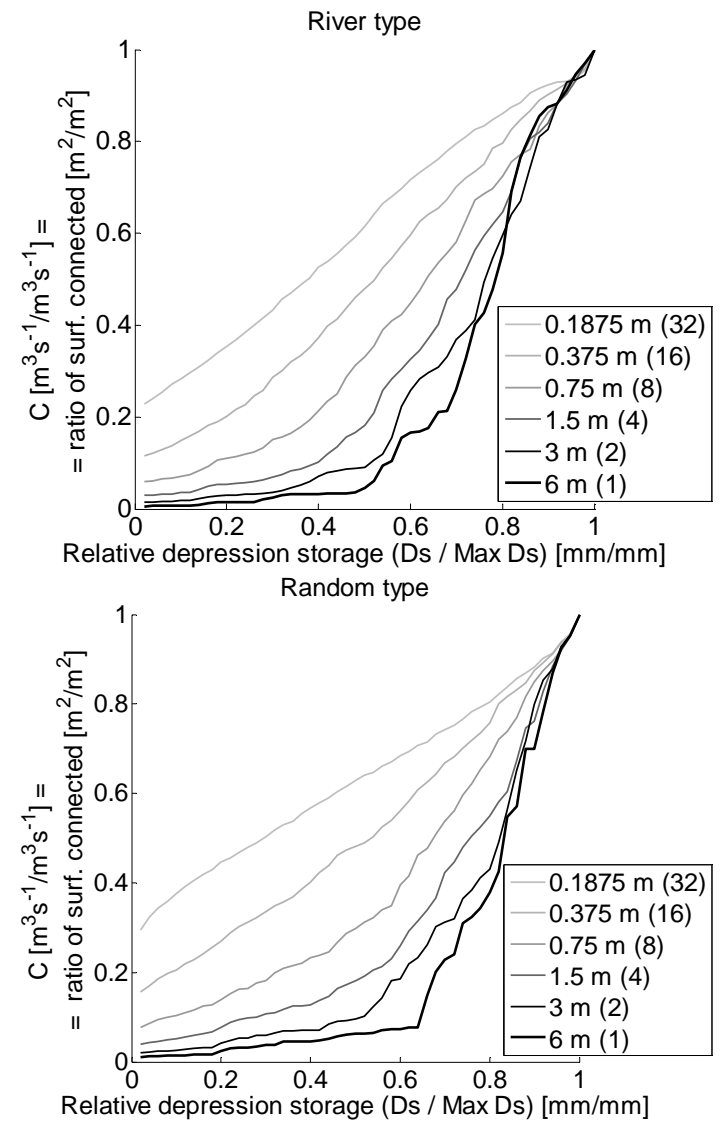

Crater type

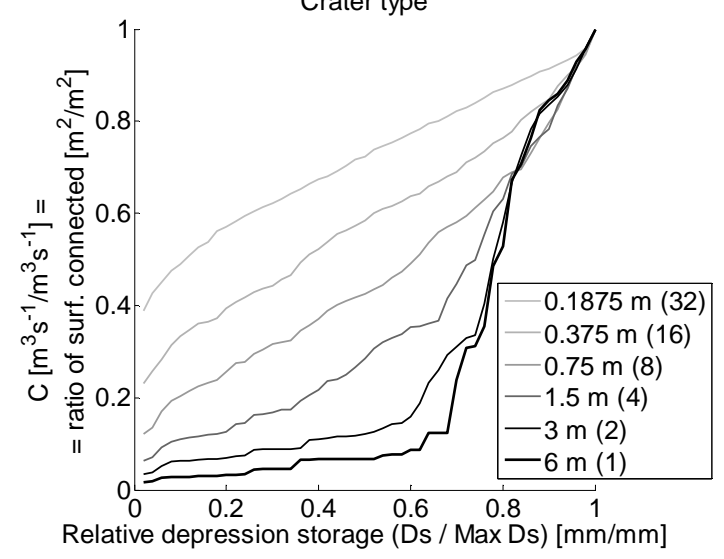

Fig. 13. Synthetic fields - effect of plot length on the average normalized RSC function for the river, random and crater type microtopographies. Depression storage (x-axis) was scaled by the maximum depression storage. The numbers in parentheses indicate the number of connectivity curves used for calculating the average normalized RSC functions. All plots are $6 \mathrm{~m}$ wide.

the maximum slope direction, which is parallel to the lateral boundaries. Since water tends to flow parallel to the lateral boundaries, the latter are less likely to block connections between depressions, and as a consequence, reducing the width has a lower impact on the connectivity process and on the MDS.
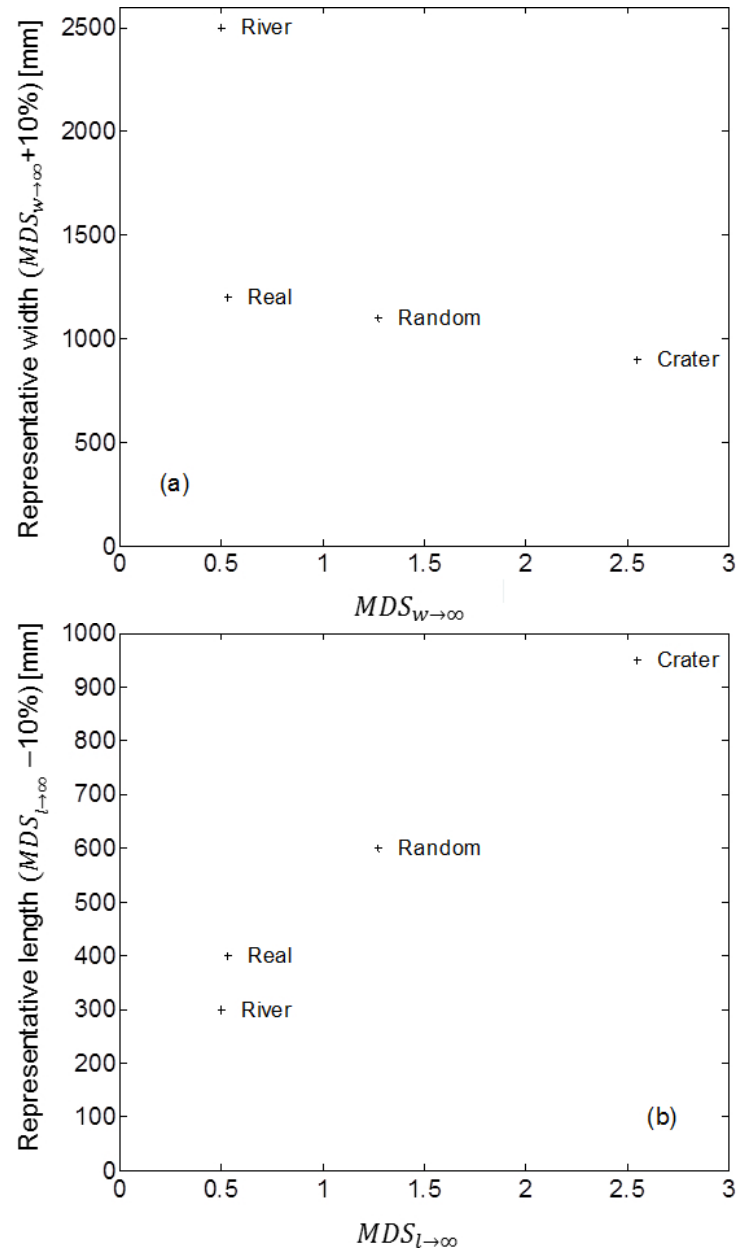

Fig. 14. (a) Representative width as a function of the MDS value for $w \rightarrow \infty$ for the four microtopography types and (b) representative length as a function of the MDS value for $l \rightarrow \infty$ for the four microtopography types.

Conversely to the width border effect, as the length is decreased the mechanism of connectivity becomes less based on the overflow of depressions since a larger proportion of depressions gets crossed by the downstream outflow boundary, and consequently the MDS gradually decreases. In the crater microtopography, which is the most sensitive to the length border effect, connectivity is driven by an overflow process for large lengths, as explained above. Nevertheless, depressions located downstream and crossed by the outflow boundary get directly connected since water does not need to overflow the system of crests. On the contrary, in the river microtopography, which is the least sensitive to the length border effect, overland flow from higher areas is stored in the system of rills. This mechanism of connectivity stores a very low volume of water since most rills are interconnected. Only locally disconnected areas, which need to overflow to get connected, store a significant volume of water. Therefore, the length border effect is considerable only when 
the downstream outflow boundary crosses a large fraction of these isolated areas, which only occurs when the length of the plots becomes very small (i.e., $\leq 300 \mathrm{~mm}$ for the river microtopography).

For the two other microtopography types, real and random, the sensitivity to the two border effects is, as expected, comprised between the two extreme cases, river and crater (Fig. 14). The width border effect affects the real and random types to a slightly higher extent than the crater type but considerably less than the river type. This suggests that the preferential direction of flow is parallel to the lateral boundaries. In addition, the connectivity mechanism for the real and random microtopographies appears to be intermediate between the overflow of depressions and the connection through rills. However, since the representative length of the real microtopography is closest to the river type, the connectivity mechanism may be predominately based on rill connections rather than the overflow of depressions.

As shown above, the sensitivity to border effects depends on the preferential direction of flow and the hydrological response of the field. Even microtopographies with the same statistical properties (Table 1) showed different sensitivities to border effects and "representative" scales. This is explained by the fact that these statistics can be considered as structural indicators whereas the RSC function is a functional indicator. Structural indicators such as the semivariogram can be useful to describe the spatial heterogeneity (Western et al., 1998), and as a heterogeneity index they can be interpreted as a link between pattern and process (Gustafson, 1998). As opposed to functional indicators, they are, however, not able to adequately account for the complexity of overland flow patterns. In the case of the synthetic fields, spatial statistics such as the semivariogram are furthermore scale-insensitive. Functional connectivity indicators like the RSC are needed to study how connectivity is affected by the border effects. Not only do functional connectivity indicators help identify the sensitivity to border effects but they may also help understand the connectivity process and discriminate between different mechanisms of connectivity.

\subsection{Scale effect on overland flow connectivity produced by changing only the width}

Apart from the border effect on the MDS when changing width, the shape of the RSC function does not seem to be considerably affected by a change in width (Figs. 5 and 10). Only when the width of the sub-areas of study is less than a certain scale $(\leq 0.375 \mathrm{~m})$ do border effects get more noticeable. In that case, they not only have an effect on the MDS but also a non-negligible impact on the shape of the RSC function. As width increases, this border effect becomes less and less noticeable both on the MDS and on the shape of the RSC function. Therefore, regions of a field wider than the minimal representative width may be considered representative of the functional connectivity of the whole field.

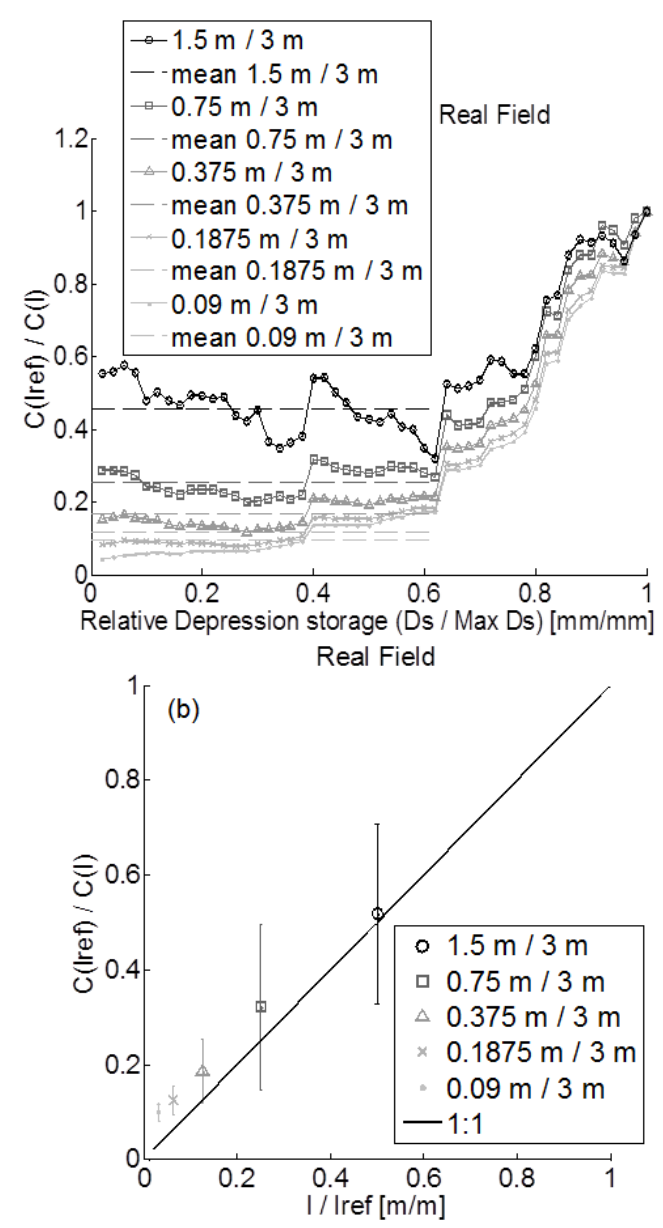

Fig. 15. Real field - scale effect when changing the length: (a) ratio of connectivities at different scales as a function of the relative depression storage. Horizontal dashed lines correspond to the mean value of the connectivity ratio calculated over the range $\mathrm{RDS}=0$ to $\mathrm{RDS}=0.62$. (b) Correlation between the scale ratios and the ratios of connectivities for the first two thirds of the RSC function. Vertical lines $=$ standard deviation. All the plots are $3 \mathrm{~m}$ wide.

\subsection{Scale effect on overland flow connectivity produced by changing only the length}

When length decreases, it not only produces a decrease in the MDS but also a considerable increase of the connectivity, as can be seen from a comparison of the normalized RSC functions (Figs. 7 and 13). In order to quantify the change in shape of the normalized RSC function, the connectivity value of the largest field $C$ ( $($ ref $)$, taken as a reference, was divided by the connectivity value of the other scales $C(l)$ for each value of relative depression storage (Figs. 15a and 16a). For the first part of the graphs (RDS $<0.5-0.7$ ), the connectivity ratios appear to oscillate around a mean value without any clear increasing or decreasing trend. In this interval the separation between two successive curves remains approximately constant, whilst for larger MDS values, the $C(l \mathrm{ref}) / C(l)$ ratio 

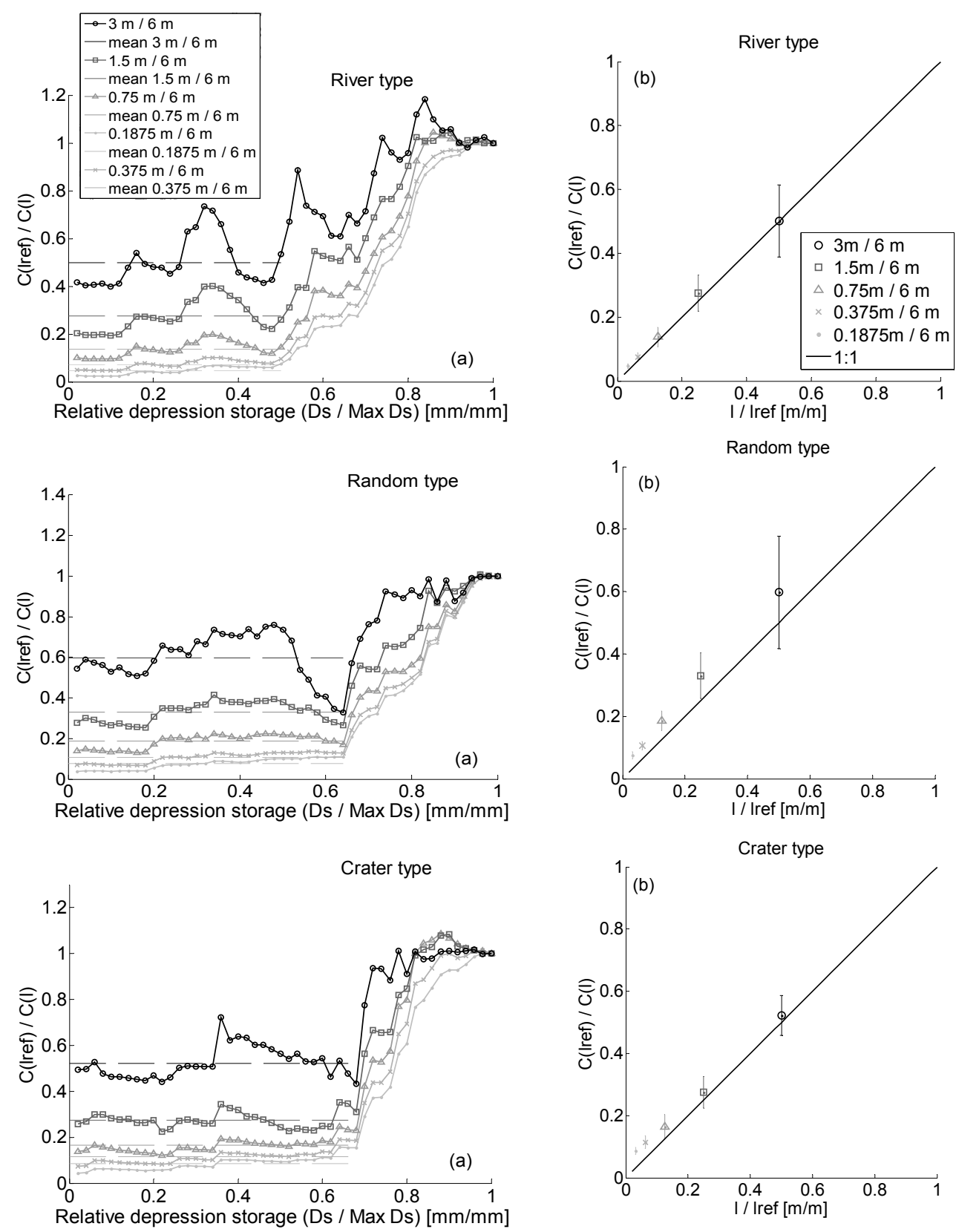

Fig. 16. Synthetic fields - scale effect when changing the length for the river, random and crater microtopographies: (a) ratio of connectivities at different scales as a function of the relative depression storage. Horizontal dashed lines correspond to the mean value of the connectivity ratio calculated over the range $\mathrm{RDS}=0$ to $\mathrm{RDS}=0.5-0.7$. (b) Correlation between the scale ratios and the ratios of connectivities for the first two thirds of the RSC function. Vertical lines = standard deviation. All the plots are $6 \mathrm{~m}$ wide.

increases rapidly and the separation between the curves progressively decreases until they all meet when the field is completely connected (relative depression storage $=1$ ).

Since for a given scale the ratio $C(l \mathrm{ref}) / C(l)$ appears to oscillate around a mean value as long as RDS $<0.5-0.7$, the values of $C(l \mathrm{ref}) / C(l)$ for this part of the function were averaged and compared to the ratio $l / l \mathrm{ref}$, where $l \mathrm{ref}=3 \mathrm{~m}$ for the real field (Fig. 15b) and $l \mathrm{ref}=6 \mathrm{~m}$ for the synthetic fields
(Fig. 16b). In this interval of RDS, both ratios show a direct correlation, implying that the rate of change of the ratio $C(l) / C$ (lref) is inversely proportional to the rate of change of the length ratio ( $/ / / \mathrm{ref})$. Since connectivity is the ratio of area connected to the outflow boundary and it increases at the same rate as the length decreases, the size of the area connected (in absolute units, $\mathrm{m}^{2}$ ) must be approximately the same for all the length scales. This is supported by Fig. 17, 

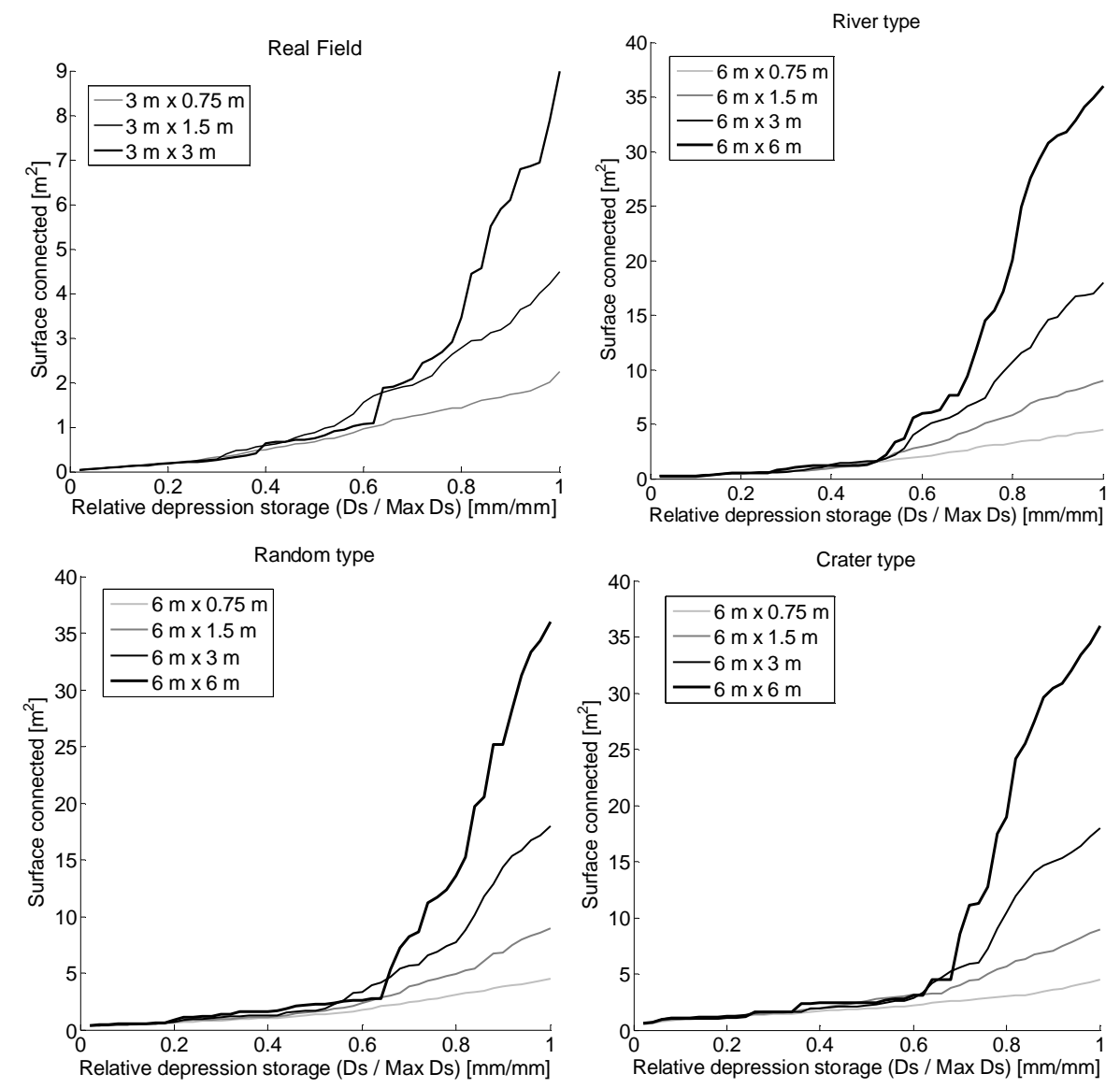

Fig. 17. Surface of the area connected to the outflow boundary, in absolute units $\left(\mathrm{m}^{2}\right)$, as a function of the relative depression storage for the four microtopography types.

and can be explained as follows. For the first part of the RSC function, which represents the first stage of the depression filling process, the depressions that are most likely to be already connected are the ones located closest to the bottom boundary. These depressions, which occupy a specific area, behave independently with regard to the rest of the depressions, further away from the bottom boundary. This connected area keeps the same size independently of the plot length except for plots shorter than this area (Figs. 17 and 2). Therefore, the connectivity $C$ gets higher when decreasing the plot length since the total area of study decreases.

After this first stage of the depression filling process (RDS $<0.5-0.7$ ), a quick process of connection of the depressions starts and depressions located further from the outflow boundary get connected. This "jump" or sharp threshold in the RSC function, which has been observed in all four microtopographies, is more noticeable for the longer plots (>3 m) (Fig. 17). This is consistent with the percolation theory (Berkowitz and Ewing, 1998), whose applicability on overland flow was demonstrated by Darboux et al. (2002a) and Lehman et al. (2007). It relies on the existence of a threshold relationship between rainfall and overland flow, caused by variations in the storage capacity and connectivity. Below a certain threshold, preferential pathways that go from the top to the bottom boundary are still not connected and the overland flow remains very low. But when this threshold is exceeded, the pathways become connected and a sharp increase in the overland flow occurs. Applying this concept, the percolation threshold can be calculated as the value of relative depression storage needed to connect the bottom boundary with the top boundary (Table 1). The values obtained for the four microtopography types are slightly higher than the threshold observed in the RSC function. This observed threshold can be assumed to represent the initiation of the connection between the bottom and the top boundary of the plot just before the complete percolation threshold is reached.

Assuming that for RDS $<0.5-0.7$ only the depressions close to the bottom boundary are connected, it may be possible to relate this stage to specific characteristics of the structural connectivity of the field, such as the average size of the depressions (puddles) or the range and sill of the semivariogram. It may then be possible to predict this first stage of the RSC function. 
These results show a great potential for the RSC function to be extrapolated from small scales to larger scales on fields with a constant slope such that a spatial autocorrelation (range) can be observed in the semivariogram. At scales larger than the minimal representative scale, once the percolation threshold is identified and predicted, we can divide the RSC function in two parts. The first one, before the percolation threshold, can be directly extrapolated by applying the inverse correlation between length and connectivity. The second part, after the percolation threshold, in which no correlation between scales has been found, may be obtained by assuming a linear relationship between depression storage and connectivity. Given that the MDS converges to a constant value for a given microtopography and that border effects become negligible beyond the minimum representative length and width (Figs. 4b, 6b, 9 and 12), it may be possible to apply the present results to scales larger than the ones used in this study. However, the present results may not be applicable in the absence of a spatial autocorrelation in the semivariogram since connectivity may then be affected by the effect of variable slope or variable random roughness inside the plot. Further research is needed to assess and confirm this.

\section{Conclusions}

In this study we investigated the behavior of overland flow connectivity using the RSC function when changing the scale (length or width) of the area of study. The results reveal that both scale effects and border effects affect overland flow connectivity at the plot scale. The changes in the RSC function with scale were consistent across four different surfaces with contrasting microtopography patterns. However, the magnitude of the scale and the border effects differed according to the hydrological response of the microtopography but could not be related to spatial statistics (e.g. the semivariogram).

No scale effect but a border effect was observed when changing the width of the plots. Hence, regions of a field with fairly short widths could be considered representative of the functional connectivity of the whole field. Based on the study of the sensitivity of the RSC function to width and length border effects, preferential direction of flows and different predominant mechanisms of connectivity on different microtopography types could be inferred. This sensitivity to border effects also allowed determining the minimal representative scale (width or length) needed to study the overland flow connectivity, in this study between $0.3 \mathrm{~m}$ and $2.5 \mathrm{~m}$ depending on the microtopography type.

A remarkable scale effect was observed in the RSC function when changing the length of the plots. At scales larger than the minimal representative scale, the RSC function showed a great potential to be extrapolated to other scales. For a given degree of filling of the depression storage, connectivity $(C)$ decreased as the plot length increased and the rate of this change of connectivity was inversely proportional to the rate of change in length. This latter observation applied only to the first stage of the RSC function (up to approx. $50-70 \%$ of filling of the maximum depression storage), after which no correlation was found between $C$ and length.

At this first stage of the RSC function, it has been observed that only the depressions close to the outflow boundary are connected. After this first stage, the RSC function shows a quick linear increase of the connectivity of the field, which is consistent with the percolation theory. These two welldifferentiated stages can potentially not only help extrapolate the whole RSC function to larger scales but also obtain information about the structural connectivity of the field.

Additional research is needed in order to predict the percolation threshold and to test the applicability of extrapolating the whole RSC function to other scales. In order to do so, a larger number of DEMs obtained from a greater variety of real soils and synthetic fields with larger sizes, different boundary conditions and connectivity characteristics must be studied.

Acknowledgements. The DEM of the real microtopography type was acquired by the USDA-ARS Agricultural Systems Research Unit in Fort Collins, Co (Jim Ascough and Timothy R. Green) with the support of the USDA-ARS National Soil Erosion Research Laboratory (F. Darboux, C. Huang, S. McAfee). We would like to thank the two referees for providing us with constructive comments and suggestions.

Edited by: E. Morin

\section{References}

Ali, G. A. and Roy, A. G.: Revisiting hydrologic sampling strategies for an accurate assessment of hydrologic connectivity in humid temperate systems, Geography Compass, 3, 350-374, 2009.

Antoine, M., Javaux, M., and Bielders, C.: What indicators can capture runoff-relevant connectivity properties of the microtopography at the plot scale?, Adv. Water Resour., 32, 12971310, 2009.

Antoine, M., Javaux, M., and Bielders, C.: Integrating subgrid connectivity properties of the micro-topography in distributed runoff models, at the interrill scale, J. Hydrol., 403, 213-223, 2011.

Antoine, M., Chalon, C., Darboux, F., Javaux, M., Bielders, C.: Estimating changes in effective values of surface detention, depression storage and friction factor at the interrill scale, using a cheap and fast method to mold the soil surface micro-topography, Catena, 91, 10-20, doi:10.1016/j.catena.2010.11.003, 2012.

Berkowitz, B. and Ewing, R. P.: Percolation theory and network modeling - applications in soil physics, Surv. Geophys., 19, 2372, 1998.

Bracken, L. B. and Croke, J.: The concept of hydrological connectivity and its contribution to understanding runoff-dominated geomorphic systems, Hydrol. Process., 21, 1749-1763, 2007.

Cerdan, O., Le Bissonnais, Y., Govers, G., Lecomte, V., van Oost, K., Couturier, A., King, C., and Dubreuil, N.: Scale effect on 
runoff from experimental plots to catchments in agricultural areas in Normandy, J. Hydrol., 299, 4-14, 2004.

Darboux, F., Davy, P., and Gascuel-Odoux, C.: Effect of depression storage capacity on overland-flow generation for rough horizontal surfaces: water transfer distance and scaling, Earth Surf. Proc. Land., 27, 177-191, 2002a.

Darboux, F., Davy, P., Gascuel-Odoux, C., and Huang, C.: Evolution of soil surface roughness and flowpath connectivity in overland flow experiments, Catena, 46, 125-139, 2002b.

Gustafson, E. J.: Quantifying landscape spatial pattern: What is the state of the art?, Ecosystems, 1, 143-156, 1998.

Julien, P. Y. and Moglen, G. E.: Similarity and length scale for spatially varied overland flow, Water Resour. Res., 26, 1819-1832, 1990.

Langhans, C., Govers, G., Diels, J., Leys, A., Clymans, W., Van den Putte, A., and Valckx, J.: Experimental rainfall-runoff data: Reconsidering the concept of infiltration capacity, J. Hydrol., 399, 255-262, 2011.

Lehmann, P., Hinz, C., McGrath, G., Tromp-van Meerveld, H. J., and McDonnell, J. J.: Rainfall threshold for hillslope outflow: an emergent property of flow pathway connectivity, Hydrol. Earth Syst. Sci., 11, 1047-1063, doi:10.5194/hess-11-10472007, 2007.

Lexartza-Artza, I. and Wainwright J.: Hydrological Connectivity: Linking concepts with practical implications, Catena, 79, 146152, 2009.

Moore, R. J.: The PDM rainfall-runoff model, Hydrol. Earth Syst. Sci., 11, 483-499, doi:10.5194/hess-11-483-2007, 2007.

Mueller, E. N., Wainwright, J., and Parsons, A. J.: Impact of connectivity on the modeling of overland flow within semiarid shrubland environments, Water Resour. Res., 43, W09412, doi:10.1029/2006WR005006, 2007.

Onstad, C. A.: Depressional storage on tilled soil surfaces, T. ASAE, 273, 729-732, 1984.

Singh, V. P. and Frevert, D.: Mathematical models of small watershed hydrology and applications, 950 pp., 2002.

Smith, M. W., Cox, N. J., and Bracken, L. J.: Applying flow resistance equations to overland flows, Prog. Phys. Geog., 31, 363387, 2007.
Stomph, T. J., de Ridder, N., Steenhuis, T. S., and van de Giesen, N.: Scale effects of Hortonian overland flow and rainfall-runoff dynamics: Laboratory validation of a process based model, Earth Surf. Proc. Land., 27, 847-855, 2002.

Taylor, P. D., Fahrig, L., Henein, K., and Merriam, G.: Connectivity Is A Vital Element Of Landscape Structure, Oikos, 68, 571-573, 1993.

Tischendorf, L. and Fahring, L.: On the usage and measurement of landscape connectivity, Oikos, 90, 7-19, 2000.

Van de Giesen, N., Stomph, T. J., and de Ridder, N.: Scale Effects on Hortonian Overland Flow and Rainfall-Runoff Dynamics in a West African Catena Landscape, Hydrol. Process., 14, 165-175, 2000.

Van Nieuwenhuyse, B. H. J., Antoine, M., Wyseure, G., and Govers, G.: Pattern-process relationships in surface hydrology: hydrological connectivity expressed in landscape metrics, Hydrol. Process., 25, 3760-3773, 2011.

Vidal Vazquez, E., Vivas Miranda, J. G., and Paz Gonzalez, A.: Characterizing anisotropy and heterogeneity of soil surface microtopography using fractal models, Ecol. Model., 182, 337-353, 2005.

Western, A. W., Bloschl, G., and Grayson, R. B.: How well do indicator variograms capture the spatial connectivity of soil moisture?, Hydrol. Process., 12, 1851-1868, 1998.

Western, A. W., Bloschl, G., and Grayson, R. B.: Toward capturing hydrologically significant connectivity in spatial patterns, Water Resour. Res., 37, 83-97, 2001.

Wood, E. F., Sivapalan, M., Beven, K., and Band, L.: Effects of spatial variability and scale with implications to hydrologic modeling, J. Hydrol., 102, 29-47, 1988.

Yair, A. and Lavee H.: Runoff Generation in arid and semi-arid zones, in: Hydrological Forecasting, edited by: Anderson, M. G. and Burt, T. P., Wiley, Chichester, UK, 183-220, 1985.

Zinn, B. and Harvey, C. F.: When good statistical models of aquifer heterogeneity go bad: A comparison of flow, dispersion, and mass transfer in connected and multivariate Gaussian hydraulic conductivity fields, Water Resour. Res., 39, 1051, doi:10.1029/2001WR001146, 2003. 